\title{
RESEARCH NOTES
}

\section{CONGRUENCES INVOLVING F-PARTITION FUNCTIONS}

\author{
JAMES SELLERS \\ Department of Science and Mathernatics \\ Cedarville College \\ Cedarville, OH 45314
}

(Received August 10, 1992)

\begin{abstract}
The primary goal of this note is to prove the congruence $\phi_{3}(3 n+2) \equiv 0(\bmod 3)$, where $\phi_{3}(n)$ denotes the number of $\mathrm{F}$-partitions of $n$ with at most 3 repetitions. Secondarily, we conjecture a new family of congruences involving $c \phi_{2}(n)$, the number of $\mathrm{F}$-partitions of $n$ with 2 colors.
\end{abstract}

KEYWORDS AND PHRASES. Congruence, partitions.

1991 AMS SUBJECT CLASSIFICATION CODE. 05A17, 11P83.

\section{INTRODUCTION.}

The two functions $\phi_{m}(n)$ and $c \phi_{m}(n)$ were introduced by George Andrews [1]. $\phi_{m}(n)$ denotes the number of $\mathrm{F}$-partitions of $n$ with at most $m$ repetitions, while $c \phi_{m}(n)$ gives the number of F-partitions of $n$ with $m$ colors. In [1], Andrews notes that there are a number of interesting congruences for both the $\phi_{m}(n)$ and $c \phi_{m}(n)$. Some of these include the following:

$$
\begin{aligned}
& \phi_{2}(5 n+3) \equiv 0(\bmod 5), \\
& c \phi_{2}(5 n+3) \equiv 0(\bmod 5), \text { and } \\
& c \phi_{m}(n) \equiv 0\left(\bmod m^{2}\right) \text { if } m \text { is prime and } m \text { does not divide } n .
\end{aligned}
$$

Louis Kolitsch [2] later found the following family of congruences:

$$
c \phi_{3}\left(3^{\alpha} n+\lambda_{\alpha}\right) \equiv 0 \begin{cases}\left(\bmod 3^{2 \alpha+2}\right) & \text { if } \alpha \text { is even } \\ \left(\bmod 3^{2 \alpha+1}\right) & \text { if } \alpha \text { is odd }\end{cases}
$$

where $\lambda_{\alpha}$ is the reciprocal of 8 modulo $3^{\alpha}$.

Given the congruences above, it would appear that the functions $c \phi_{m}(n)$ satisfy more partition congruences than do the functions $\phi_{m}(n)$. However, the primary goal of this paper is to prove a new congruence involving $\phi_{3}(n)$, not $c \phi_{3}(n)$. The proof is very elementary, similar to the proof given by Andrews for congruences (1.1) and (1.2) above.

2. A NEW CONGRUENCE INVOLVING $\phi_{3}$.

The congruence to be proven is the following:

THEOREM: For all $n \geq 1$,

$$
\phi_{3}(3 n+2) \equiv 0 \quad(\bmod 3) .
$$


Proof: From Andrews [1; p. 12], we know that

$$
\begin{aligned}
\sum_{n=0}^{\infty} \phi_{3}(n) q^{n} & =\frac{1}{(q ; q)_{\infty}^{3}} \sum_{m=-\infty}^{\infty} q^{3 m^{2}} \sum_{n=-\infty}^{\infty}(-1)^{n} q^{n^{2}} \\
& \equiv \frac{1}{\left(q^{3} ; q^{3}\right)_{\infty}} \sum_{m=-\infty}^{\infty} q^{3 m^{2}} \sum_{n=-\infty}^{\infty}(-1)^{n} q^{n^{2}} \quad(\bmod 3)
\end{aligned}
$$

The theorem is then proved provided we show that all coefficients of $q^{3 n+2}$ in the double sum above are divisible by 3 . In order to get a contribution to $q^{3 n+2}$, we must have

$$
\begin{aligned}
3 m^{2}+n^{2} & \equiv 2(\bmod 3) \\
\Longrightarrow n^{2} & \equiv 2(\bmod 3) .
\end{aligned}
$$

However, there is no integer $n$ which satisfies this congruence. Hence, the theorem is proved.

3. CONCLUDING REMARKS.

It is interesting to note the "pairs" of congruences above, namely (1.1) and (1.2), as well as (1.4) and (2.1). Note that the case $\alpha=1$ in (1.4) above is

$$
c \phi_{3}(3 n+2) \equiv 0 \quad\left(\bmod 3^{3}\right) .
$$

Moreover, it is also interesting that the second pair involves an infinite family of congruences, while the first pair does not. However, thanks to empirical data which is easily calculated using the generating function for $c \phi_{2}$, we can conjecture the following family of congruences similar to (1.4) above:

CONJECTURE: For all $n \geq 1$,

$$
c \phi_{2}\left(5^{\alpha} n+\lambda_{\alpha}\right) \equiv 0 \quad\left(\bmod 5^{\alpha}\right)
$$

where $\lambda_{\alpha}$ is the reciprocal of 12 modulo $5^{\alpha}$. The first case of this conjecture is congruence (1.2) above.

\section{REFERENCES}

1. ANDREWS, G. E., Generalized Frobenius Partitions, Memoirs of the American Mathematical Society, Volume 301, Providence, RI, May 1984.

2. KOLITSCH, L., A Congruence for Generalized Frobenius Partitions with 3 Colors Modulo Powers of 3, in: B. C. Berndt, et. al., ed., Analytic Number Theory, Proceedings of a Conference in Honor of Paul T. Bateman, Birkhauser Boston, Boston, MA, 1990, 343-348. 


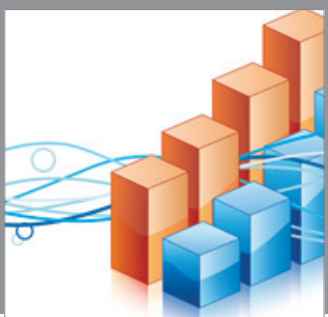

Advances in

Operations Research

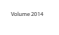

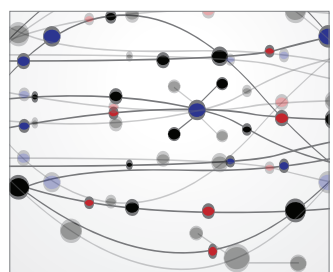

\section{The Scientific} World Journal
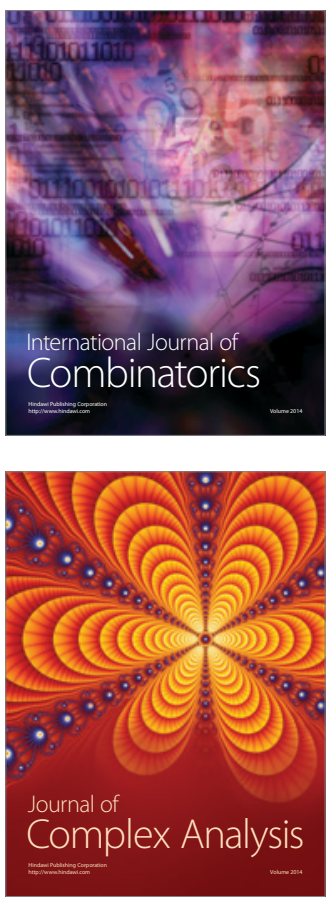

International Journal of

Mathematics and

Mathematical

Sciences
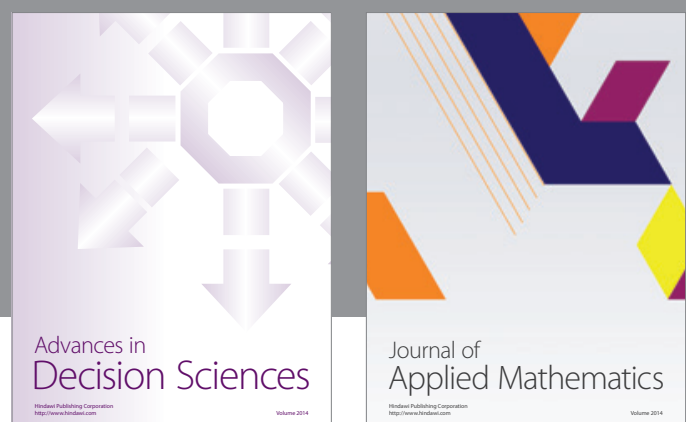

Journal of

Applied Mathematics
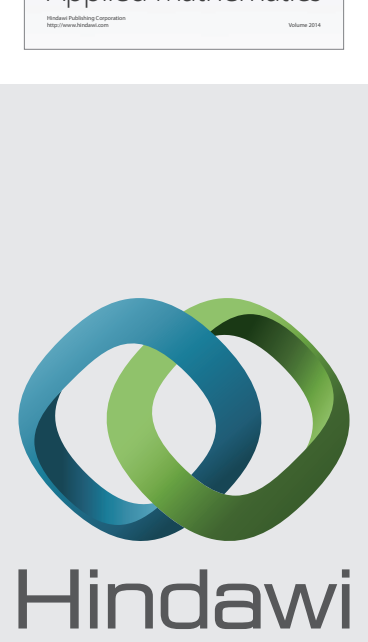

Submit your manuscripts at http://www.hindawi.com
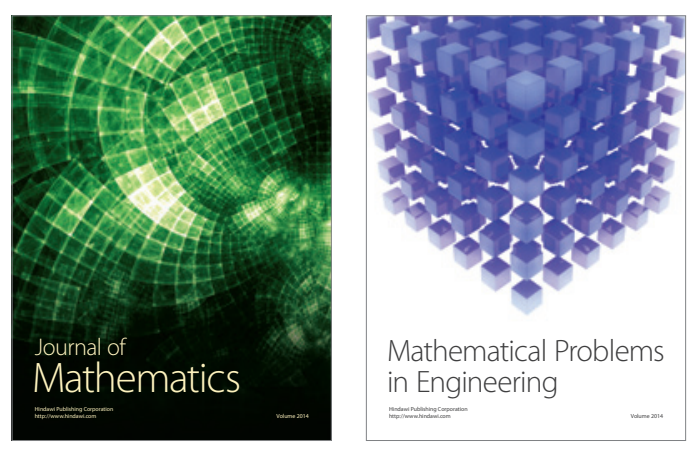

Mathematical Problems in Engineering
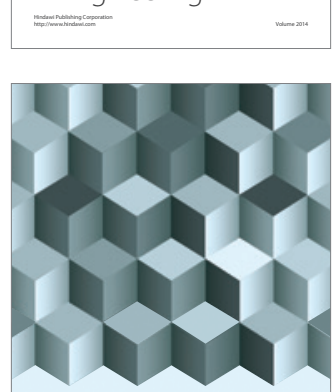

Journal of

Function Spaces
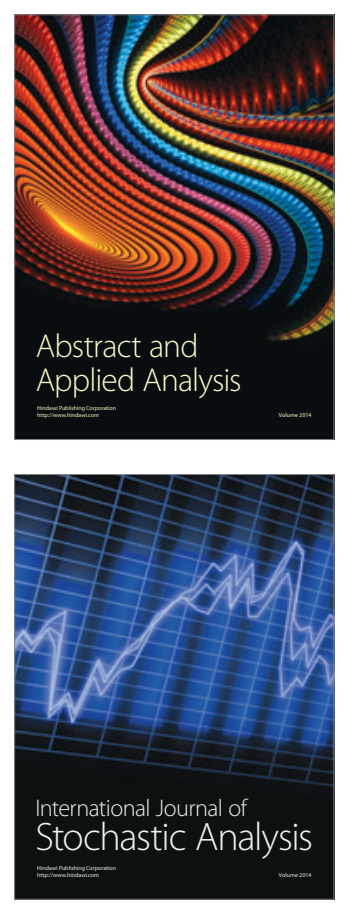

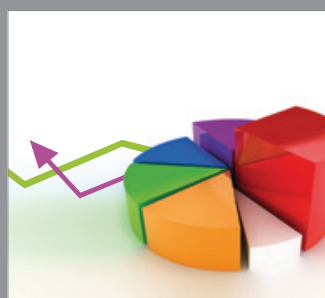

ournal of

Probability and Statistics

Promensencen
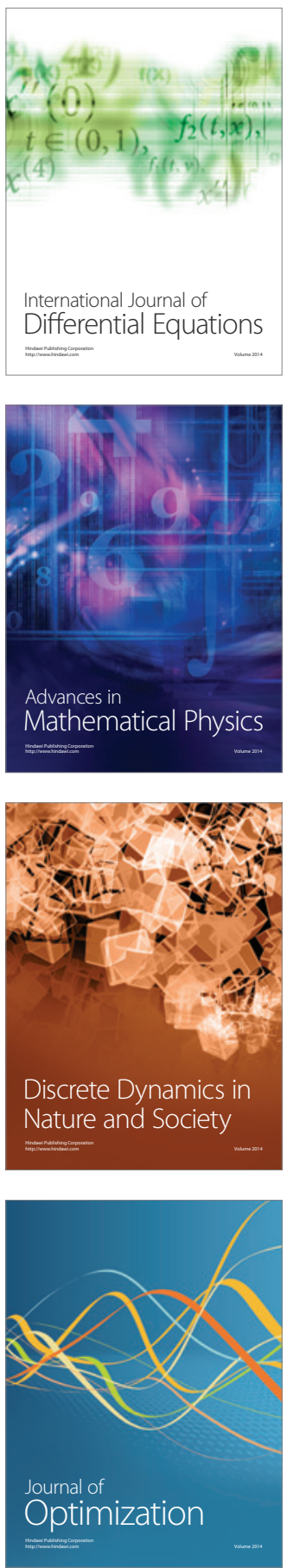